\title{
From A Shared Single Display Application to Shared Virtual Space Learning Application
}

\author{
Gary Loh Chee Wyai ${ }^{1}$, Cheah Waishiang ${ }^{2}$, Muhammad Asyraf Bin Khairuddin ${ }^{2}$ and \\ Chen Chwen Jen ${ }^{2}$ \\ ${ }^{1}$ School of Computing, University College of Technology Sarawak, 96000, Sibu, Sarawak, Ma- \\ laysia \\ ${ }^{2}$ Faculty of Computer Science \& IT, UNIMAS, Kota Samarahan, Sarawak, Malaysia \\ wscheah@unimas.my
}

\begin{abstract}
Shared single display support the learning environment through multiple devices like mouse, keyboard or mobile phone. To what extend it is useful for university learning? We had identified some challenges in using shared single display. This paper reports the challenges in using a shared single display for learning activity in university. From the challenges, we explored a shared virtual space and the finding is reported in this paper. It is interesting to claim that shared virtual space is more promising in term of learning activities and development. The shared virtual space is easy to manage. However, creating sustainable and collaborative, scalable learning virtual space is a challenge and worth to explore in future.
\end{abstract}

Keywords: Gaming AI, Android Game Development, 3rd Person Shooting Game, Artificial Intelligence

\section{Introduction}

The computer-supported collaborative learning (CSCL) is a software application developed to support collaborative learning. It can enhance student's skills, receive supports by peers, serve as communication medium etc. [3]. They are several kinds of CSCL. Among them, a shared single display (SSD) groupware is used in a classroom setting [4]. SSD enables a group of users to share the same concurrent display (which can be a large display or just a monitor), where each member will have his or her own input device to simultaneously interact with the system. This allows collaborators to benefit from the advantages of face-to face interactions as they are co-located; as well as be able to observe the non-verbal communication among members such as excitement and enthusiasm of the collaborating parties. With the multi-mice setting, students can work individually or collaboratively. The students will work within their own region or in a shared single display. Each region allows the students to provide the answer accordingly by clicking on the button provided or drag and drop the entire answer. The question is presented at the left handle corner of the screen. In this case, the students require to fill in the answers based on the questions given. Each player needs to provide an answer(s) when given a question. The students need to answer each question and 
submit all the answers before proceeding to the next question. This is important to engage the students during the answering session.

It has been reported that shared single display is useful for primary schools, but can it benefit the university students? This paper investigates the adoption of a shared single display technology for learning the programming concept. A single shared display is developed in this study to create a collaborative learning environment in the tutorial room. In this case, a group of students will use a computer to answer a set of tutorials and learn collaboratively. The effectiveness of this technology is presented in this paper. In addition, the issues and limitation of this technology are presented in this paper. The results from this finding has introduced a new insight for collaborative system development in a classroom to learn programming concept in which a virtual shared space is investigated and reported.

Section 2 presents the works on shared single display through multi-mice technology. It covers the findings of experimenting shared single display in learning the concept of Data structure and Algorithm. Section 3 presents the proposed shared virtual space as an alternative method for learning technology. The findings of both experiments are presented in Section 4. The paper is concluded in Section 5.

\section{$2 \quad$ Shared Single Display}

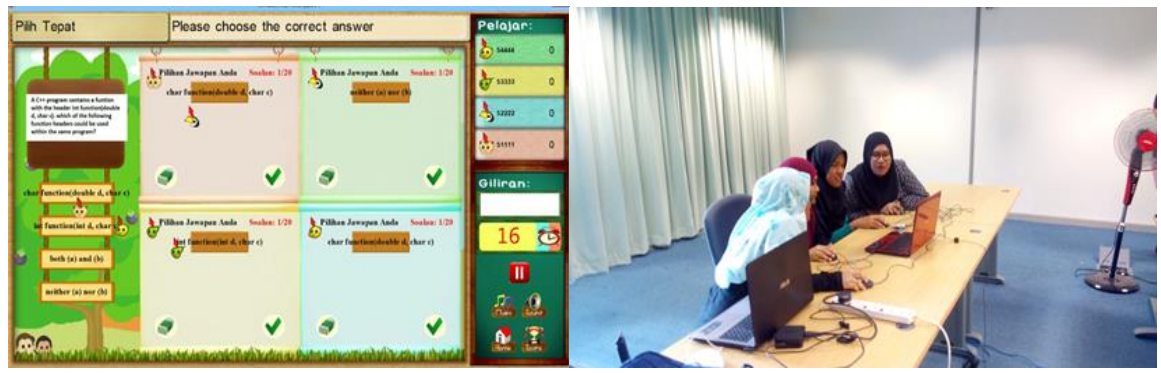

Fig. 1. Multi-mice shared single display application

This section presents the experiment setting for the research on shared single display. Multi-mice technology is adopted to develop a shared single display among the undergraduate students, as shown in Figure 1. The subject of the experiment is TMF1434, Data Structure and Algorithm (DSA). This is one of the subjects that seem to be difficult to deliver due to the complexity and time constraint. It is always a challenge to conduct this course as students need to learn a new programming concept (e.g. Object-oriented framework) within the first two weeks of a semester. Meanwhile, students failed to relate the theory of DSA to the problem-solving due to much times were taken to understand the theory of DSA. Although students can consult lecturers after every classes or tutorials, the clarification of the topics only limited to a small number of students. Furthermore, there are many students feel hesitant to discuss with their lecturers or ask questions in the class or tutorials. They would prefer to consult their friends on the 